\title{
High-Efficiency Output Pressure Performance Using Capacitive Micromachined Ultrasonic Transducers with Substrate-Embedded Springs
}

\author{
Byung Chul Lee ${ }^{1,2, *(\mathbb{D})}$, Amin Nikoozadeh ${ }^{3}$, Kwan Kyu Park ${ }^{4(\mathbb{D})}$ and Butrus T. Khuri-Yakub ${ }^{3, *}$ \\ Center for BioMicrosystems, Korea Institute of Science and Technology, Seoul 02792, Korea \\ Department of Biomedical Engineering, University of Science and Technology, Daejeon 34113, Korea \\ Department of Electrical Engineering, Stanford University, CA 94305, USA; amin.nikoozadeh@gmail.com \\ 4 Department of Mechanical Engineering, Hanyang University, Seoul 04763, Korea; kwankyu@hanyang.ac.kr \\ * Correspondence: bclee@kist.re.kr (B.C.L.); khuri-yakub@stanford.edu (B.T.K.-Y.); \\ Tel.: +82-2-958-5748 (B.C.L.); +1-650-723-0718 (B.T.K.-Y.)
}

Received: 15 June 2018; Accepted: 26 July 2018; Published: 2 August 2018

check for updates

\begin{abstract}
Capacitive micromachined ultrasonic transducers (CMUTs) with substrate-embedded springs offer highly efficient output pressure performance over conventional CMUTs, owing to their nonflexural parallel plate movement. The embedded silicon springs support thick Si piston plates, creating a large nonflexural average volume displacement efficiency in the operating frequency range from 1-3 MHz. Static and dynamic volume displacements of the nonflexural parallel plates were examined using white light interferometry and laser Doppler vibrometry. In addition, an output pressure measurement in immersion was performed using a hydrophone. The device showed a maximum transmission efficiency of $21 \mathrm{kPa} / \mathrm{V}$, and an average volume displacement efficiency of $1.1 \mathrm{~nm} / \mathrm{V}$ at $1.85 \mathrm{MHz}$ with a low DC bias voltage of $55 \mathrm{~V}$. The device element outperformed the lead zirconate titanate (PZT) ceramic HD3203, in the maximum transmission efficiency or the average volume displacement efficiency by 1.35 times. Furthermore, its average volume displacement efficiency reached almost $80 \%$ of the ideal state-of-the-art single-crystal relaxor ferroelectric materials PMN-0.33PT. Additionally, we confirmed that high-efficiency output pressure could be generated from the CMUT device, by quantitatively comparing the hydrophone measurement of a commercial PZT transducer.
\end{abstract}

Keywords: capacitive micromachined ultrasonic transducers (CMUTs); substrate-embedded springs; nonflexural piston movement; high-efficiency output pressure

\section{Introduction}

Capacitive micromachined ultrasonic transducers (CMUTs), are microelectromechanical system devices that make use of electrostatic actuation and detection of ultrasound, using multiple top moving plate geometries separated from the supportive substrate by vacuum gaps. Because CMUTs offer the advantages of improved fractional bandwidth (FBW), large operating frequency range, ease of fabrication from very small to large arrays with individual electrical connections, and simple integration with electronics, it has been proven through many demonstrations that this technology is one of the best candidates for advancing the state-of-the-art in medical ultrasound imaging [1]. Four-dimensional (4D) ultrasound imaging with a large number of two-dimensional (2D) CMUT array elements [2]; probe development of 2D CMUT array using row-column addressed electrodes [3,4]; compensated three-dimensional (3D) imaging techniques using column-row addressing architecture with 2D CMUT arrays [5,6]; volumetric intracardiac imaging with miniature one-dimensional (1D) 
and 2D ring arrays on catheters [7-10]; switchable high-intensity focused ultrasound (HIFU) therapy and 4D imaging using a single 2D CMUT array [11]; and photoacoustic imaging with 1D linear CMUT probes [12] are among the state-of-the-art demonstrations in medical applications.

Although the CMUT has received attention for the past two decades due to its versatility and advantages for medical applications, some basic improvements are necessary to further enhance its performance compared to piezoelectric transducers. Because of its inherent transduction mechanism, the transduction efficiencies (transmission efficiency and receiving sensitivity) and FBW, are so closely related that a performance trade-off is inevitable in a conventional CMUT design. For high transduction performance, the maximum average displacement of the CMUT plate has to be achieved with the given vacuum gap height. However, owing to its inherent flexural motion, as shown in Figure 1, the vacuum gap height in the CMUT structure is partially utilized for its transduction efficiency. Several solutions to these disadvantages, including CMUTs with piston-shaped membranes [13], dual-electrode CMUT with non-uniform membranes [14], indirectly clamped CMUTs [15], CMUTs with multiple moving membranes [16], and a collapse-mode CMUT with an embossed membrane [17] have been proposed.


Figure 1. Cross-sectional schematic drawings of an element with 3 cells of a conventional capacitive micromachined ultrasonic transducers (CMUT). (Top) Initial state before applying DC and AC voltage, and (Bottom) flexural deformation of the moving plate due to electrostatic force.

In this paper, we introduce a CMUT with substrate-embedded springs which improve the transduction efficiency, particularly regarding output pressure performance at a lower voltage due to its piston-like motion. A theoretical comparison between the conventional CMUT and the proposed CMUT with substrate-embedded springs is provided, to demonstrate high efficiency on the transmit performance of the proposed ultrasonic transducer. Several micromachining techniques were utilized to build the CMUT with substrate-embedded springs. After fabricating the devices, we measured the electrical impedance using an impedance analyzer; and the acoustic transmit performances using a hydrophone and a laser Doppler vibrometer. We quantitatively compared the transmit performance of the proposed CMUT device with two PZT ceramic materials, considered one of the state-of-the-art single crystal piezoelectric materials, and a commercially available piezoelectric probe.

\section{Working Principle}

The CMUT with substrate-embedded springs has a compliant silicon post or rod structure, supporting the rigid thick moving plate or piston top plate, as shown in Figure 2. As compared to the operation principle of the conventional CMUT, the compliant silicon post or rod structure provides the spring a constant in the mass-spring-damper system. Since the compression and restoration of the 
plate movement are not provided by the plate itself, but from the separate silicon springs, the CMUT with substrate-embedded springs resembles an ideal electrostatic piston with parallel movement.

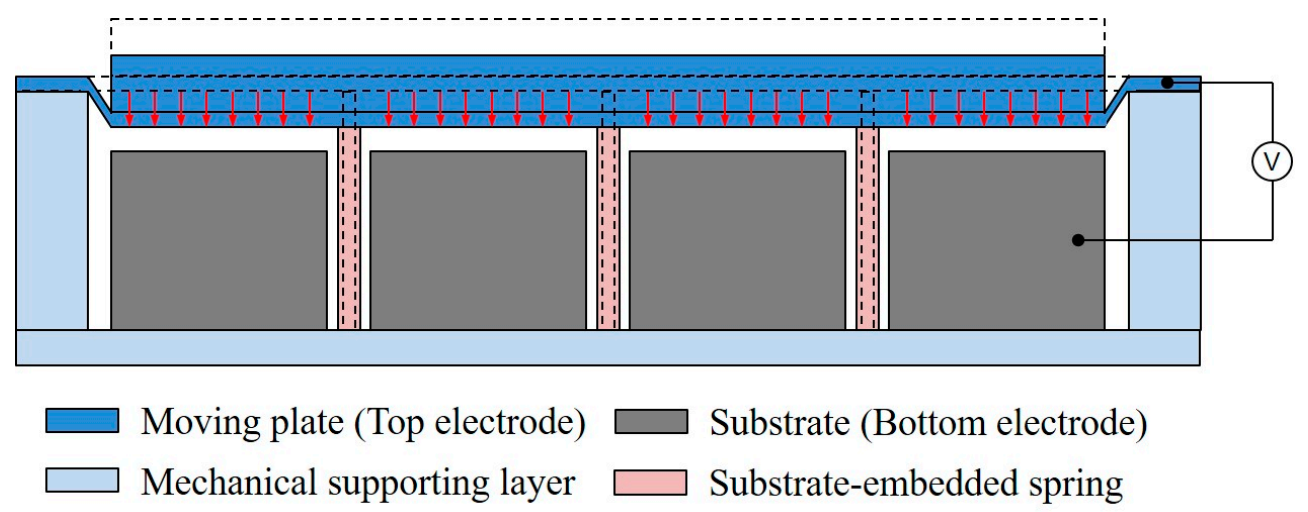

Figure 2. Cross-sectional schematic drawings of an element of CMUT with substrate-embedded springs. The dashed line represents the initial state of the CMUT with substrate-embedded springs before applying DC and AC voltage.

To compare the average displacement between the conventional CMUT and the CMUT with substrate-embedded springs, the static average displacement of a conventional circular CMUT was calculated using Kirchhoff's thin plate bending theory [18] as

$$
\begin{gathered}
\frac{P}{D}=\nabla^{2} \nabla^{2} u \text { where } D=\frac{2 h^{3} E}{3\left(1-v^{2}\right)} \\
u=\frac{P_{0} b}{8 a^{2} D}\left\{\begin{array}{l}
\left(a^{2}-b^{2}\right)\left(a^{2}+r^{2}\right)+2 a^{2}\left(b^{2}+r^{2}\right) \ln \left(\frac{b}{a}\right) r \leq b \\
\left(a^{2}+b^{2}\right)\left(a^{2}-r^{2}\right)+2 a^{2}\left(b^{2}+r^{2}\right) \ln \left(\frac{r}{a}\right) r>b
\end{array}\right. \\
u_{\text {avg }}=\frac{1}{A_{\text {tot }}} \int_{A_{\text {tot }}} u d A
\end{gathered}
$$

where $P_{0}$ is the uniform line external pressure distributed along a circle with radius $b, a$ is a typical radius of the whole plate, $u$ is the corresponding displacement, $D$ is the flexural rigidity of the plate, $h$ is the plate thickness, $E$ is the plate material's Young's modulus, $v$ is the plate material's Poisson's ratio, and $A_{\text {tot }}$ is the total plate area. We assumed that the plate had no internal tensile or compressive stress so that the Kirchhoff's equation could be expressed merely as Equation (1). From the modified Bessel functions and the assumption of the negligible internal stress in the plate, the solutions for the circular CMUT can be greatly simplified as Equation (2). With the segmentation of the plate and superposition of the displacement [19], the calculation result of $u_{\text {avg }}$ showed that the CMUT plate with substrate-embedded springs can displace on average almost three times, i.e., 2.78 at $80 \%$ of the pull-in voltage and 2.85 at $99 \%$ of the pull-in voltage, more than the conventional CMUT plate. Thus, it can be surmised that the CMUT with substrate-embedded springs transmits ultrasound wave more efficiently, promising improvements in performance by achieving a higher average displacement for a given electric field. The output pressure $P$ is proportional to the average displacement based on the acoustic wave theory [20]:

$$
P=\operatorname{Re}\left(Z_{m} V\right)=\operatorname{Re}\left(\mathrm{Z}_{m}\right) \times \omega \times \bar{x}
$$

where $Z_{m}$ is the mechanical impedance of the medium, $V$ is the velocity of the acoustic wave particle, $\omega$ is the operating frequency, and $\bar{x}$ is the average displacement amplitude of the acoustic wave particle, which is equivalent to the plate displacement. 


\section{Design and Fabrication}

For the design of the CMUT structure with substrate-embedded springs, we previously simulated and investigated the finite element analysis (FEA) model with a commercial simulator (ANSYS, Inc., Canonsburg, PA, USA) [21]. Based on the simulation results, four $100 \mu \mathrm{m} \times 100 \mu \mathrm{m}$ silicon piston top plates with thicknesses of $20 \mu \mathrm{m}$ were used to compose a 2D CMUT element, with an operating frequency around $2 \mathrm{MHz}$ in immersion. Each piston top plate was attached to the substrate with nine silicon post springs, where each spring was $4 \mu \mathrm{m}$ in diameter and $50 \mu \mathrm{m}$ in length. To investigate the independence between the spring and the mass components in the piston top plate, the top plates were patterned as two different types; one has a plane feature and the other has a truss structure.

Wafer bonding of two silicon-on-insulator wafers that have undergone a deep reactive ion etching process, and a chemical mechanical polishing process, provides good dimensional control in fabricating the structure. The detailed fabrication process was similar to the previous work [22]. The bottom side starting substrate was a silicon-on-insulator (SOI) wafer having a device layer of $50 \mu \mathrm{m}, 2 \mu \mathrm{m}$ thick BOX layer, and $350 \mu \mathrm{m}$ thick handle layer from Ultrasil (Hayward, CA, USA). The crystal orientation of the SOI device layer was set up to be (100). To provide the bottom electrode, the electrical resistivity of the device layer was chosen as $0.003 \Omega \mathrm{cm}$. The top side 8-inch SOI substrate had a device layer of $200 \mathrm{~nm}, 150 \mathrm{~nm}$ thick BOX layer, and $725 \mu \mathrm{m}$ thick handle layer from Soitec (Grenoble, France). To increase the conductivity of the device layer which is served as the top electrode, we epitaxially grew $50 \mathrm{~nm}$ highly doped silicon layer on the $200 \mathrm{~nm}$ thick device layer. The $3 \times 10^{19} \mathrm{~cm}^{-3}$ phosphorus was added during the epitaxial growth from LSQI (Reno, NV, USA). Our facility provided most of the process in 4-inch bases, so that the 8-inch SOI wafer was cut into two 4-inch wafers from Ultrasil (Hayward, CA, USA).

First, to accurately control the vacuum gap height, double oxidation with two steps of $200 \mathrm{~nm}$ oxidation after $250 \mathrm{~nm}$ oxidation led to the vacuum gap height of $150 \mathrm{~nm}$ (Figure 3a,b). The partially etched silicon block was formed to connect all the four cells into one element using RIE process (Figure 3c). The DRIE process defined the 2D CMUT element and the lateral dimensions of the silicon post springs (Figure 3d). The donut shape mask was used, having a trench opening width of $3 \mu \mathrm{m}$. In this case, the pitch of the nine posts was set to be $30 \mu \mathrm{m}$. The top side SOI wafer was roughly aligned with the bare eye on top of the bottom processed wafer. Before placing the top SOI wafer, RCA1 cleaning process was conducted to provide chemical activation of the two bonding surfaces. The wafer bonding process was done under $600 \mathrm{~N}$ of a bonding force with the chamber pressure of $4 \times 10^{-5} \mathrm{mbar}$ (Figure 3e). We put the bonded wafer for $9 \mathrm{~h}$ in the annealing furnace, with the condition of nitrogen ambient and $1100{ }^{\circ} \mathrm{C}$. Subsequently, the handle layer of the top wafer was ground and polished, until the plate thickness reached $20 \mu \mathrm{m}$ (Figure 3f). To accurately define the truss structure, $100 \mathrm{~nm}$ of silicon dioxide mask was grown and patterned (Figure 3g). Sequentially, the top plate was defined using DRIE (Figure 3g), and all the layers, such as $150 \mathrm{~nm}$ BOX layer, $250 \mathrm{~nm}$ device layer, and $250 \mathrm{~nm}$ silicon dioxide layer, were consecutively etched to make electrical access to the bottom electrodes (Figure 3i-k). Finally, $500 \mathrm{~nm}$ aluminum was deposited and patterned, as shown in Figure 31. 


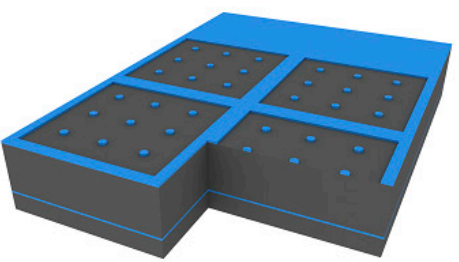

(a)

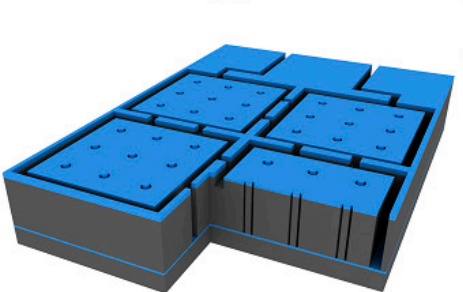

(d)

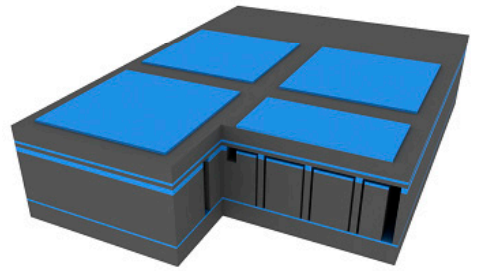

(g)



(j)

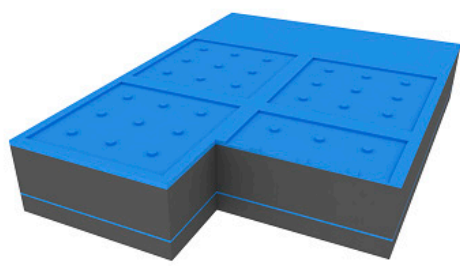

(b)

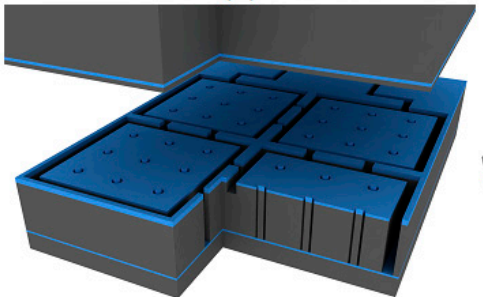

(e)

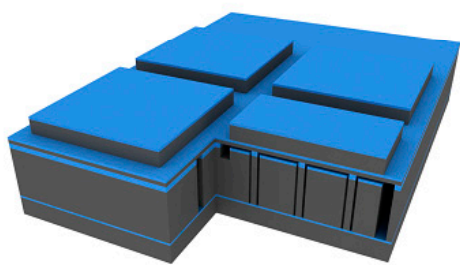

(h)

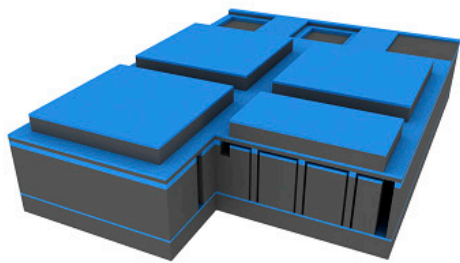

(k)

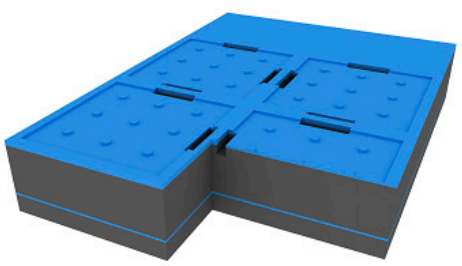

(c)

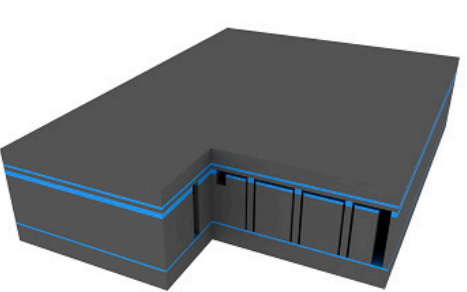

(f)

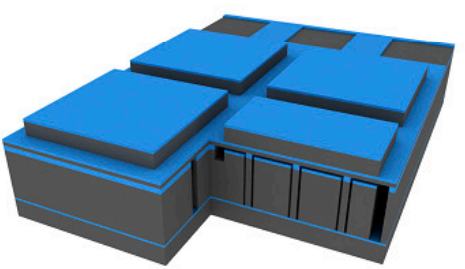

(i)

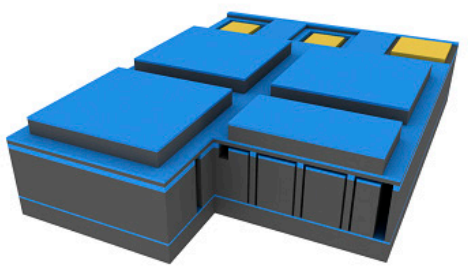

(1)

Silicon(Si)

Silicon Dioxide $\left(\mathrm{SiO}_{2}\right)$

Aluminum(Al)

Figure 3. The fabrication process flow of the CMUT with substrate-embedded springs. (a) $250 \mathrm{~nm}$ silicon dioxide patterning for vacuum gap area; (b) Thermal oxidation for defining $150 \mathrm{~nm}$ vacuum gap height; (c) Formation of electrical connection bridges using RIE; (d) DRIE process step for defining four CMUT cells and 36 silicon spring posts; (e) Direct wafer fusion bonding of the processed bottom SOI wafer and a top blank SOI wafer; (f) Wafer grinding and polishing for piston top plate; (g) Thermal oxidation and patterning for top plate mask; (h) DRIE step for piston top plates; (i) BOX layer opening for electrical contacts; (j) Silicon device layer etching for bottom electrode access; (k) BOX layer etching for bottom electrodes; (1) Metal deposition and patterning for three electrode pads.

Two different types of the fabricated 2D CMUT elements, the plane type and the truss type, is illustrated in Figure $4 a$. Figure 4 b, shows the top-view colored field emission scanning electron microscopy (SEM) images of the two different 2D CMUT elements. The mass of the truss structure was defined using the photolithographic process and was $84.6 \%$ of the mass of the plane structure. Focused ion beam (FIB) milling revealed that the embedded silicon post spring was well-bonded to the piston top plate, as shown in Figure 4c. In the picture, the pink colored area represents silicon debris redeposited during the milling process. Figure $4 \mathrm{~d}$, shows a magnified SEM picture of the vacuum gap area. The vacuum gap was $150 \pm 2 \mathrm{~nm}$, the thickness of the silicon top plate as the top electrode was $250 \pm 5 \mathrm{~nm}$, and the thickness of the silicon dioxide insulating layer was $200 \pm 3 \mathrm{~nm}$. This confirmed our tight vertical dimension control from the fabrication process. 


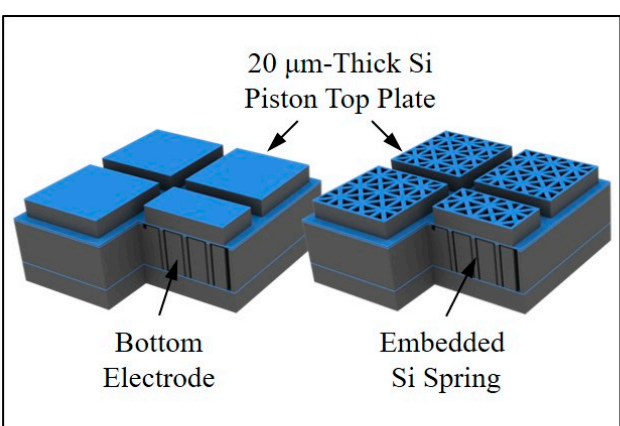

(a)

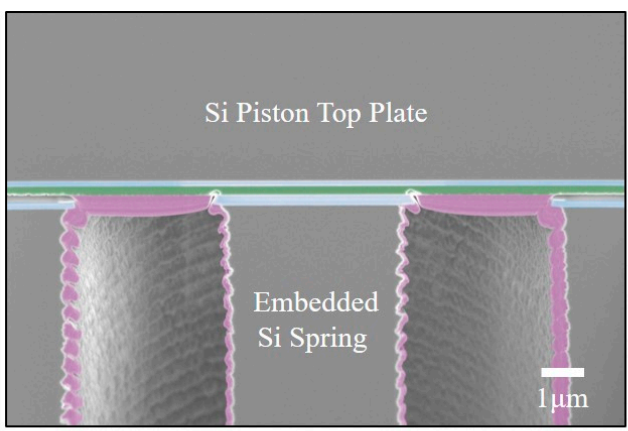

(c)

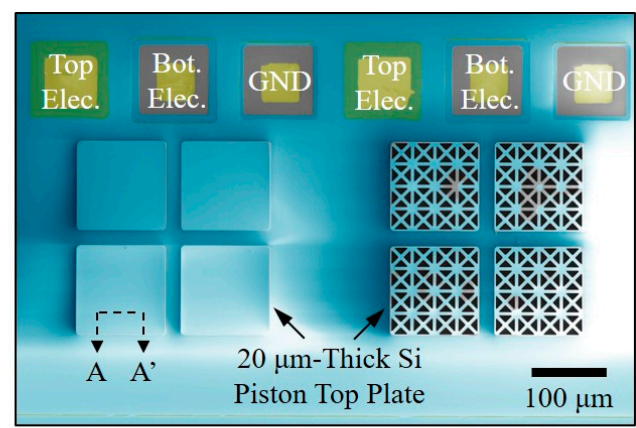

(b)

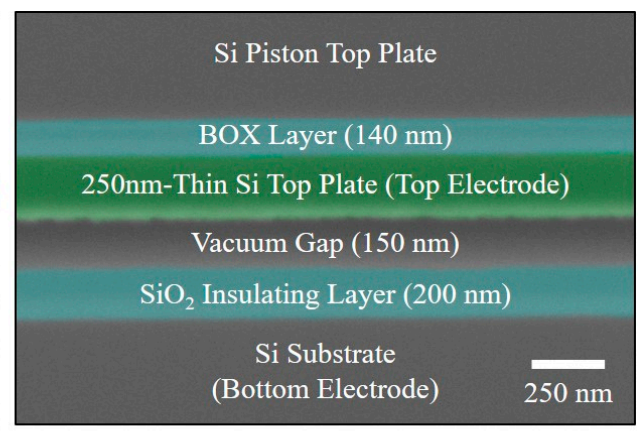

(d)

Figure 4. (a) A perspective schematic drawing of two different 2D CMUT elements with substrateembedded springs. (b) A top-view colored SEM image of the two different 2D CMUT elements. (c) A cross-sectional SEM image of an embedded Si spring bonded with a Si piston top plate (the crosssectional line is shown in Figure 3b). (d) A magnified cross-sectional SEM image of the vacuum gap area.

\section{Experimental Results}

The amplitude (Figure 5a) and phase (Figure 5b) parts of the electrical input impedance of the plane and truss 2D CMUT with substrate-embedded springs, were measured using an impedance analyzer (Agilent 4294A, Santa Clara, CA, USA). The DC bias from the high voltage power supply (SRS PS310, Stanford Research Systems, Stanford, CA, USA) was applied to the 2D CMUT through the DC arm of the bias T circuit. A small signal AC voltage of $100 \mathrm{mV}$, was superimposed through the bias $\mathrm{T}$ circuit. After verifying the pull-in voltage of $78 \mathrm{~V}$, the bias voltage was set to be $40 \mathrm{~V}$. Because the mass of the truss 2D CMUT was $84.6 \%$ of the mass of the plane structure, the resonant frequency of the truss 2D CMUT showed higher resonant and anti-resonant peaks, in Figure 5. We also verified that the resonant frequencies from ANSYS, deviated less than $6 \%$ from the impedance measurement results.

A high-resolution white light interferometer (CCI HD, Taylor Hobson, Inc., Leicester, UK) was used to characterize the static displacement of the CMUT elements with substrate-embedded springs, as a function of the DC biases (Figure 6). The static deflection of each top plate with no DC bias voltage, was measured to set the baseline for the static displacement. This ensured no significant flexural bending of the top plate for each plate type from atmospheric pressure, as compared to the typical CMUT, which showed the apparent flexural bending feature at the center of its plate, by the pressure difference between the vacuum cavity and the atmosphere. As shown in the 2D profile plots in Figure 6, the nonflexural parallel plate displacement is demonstrated for various DC biases. Since the number of silicon post springs was the same between the plane and truss 2D CMUTs, the pull-in voltage of the devices was apparently measured to be the same value of $78 \mathrm{~V}$, and the same amount of static displacement for the same DC bias was observed. 


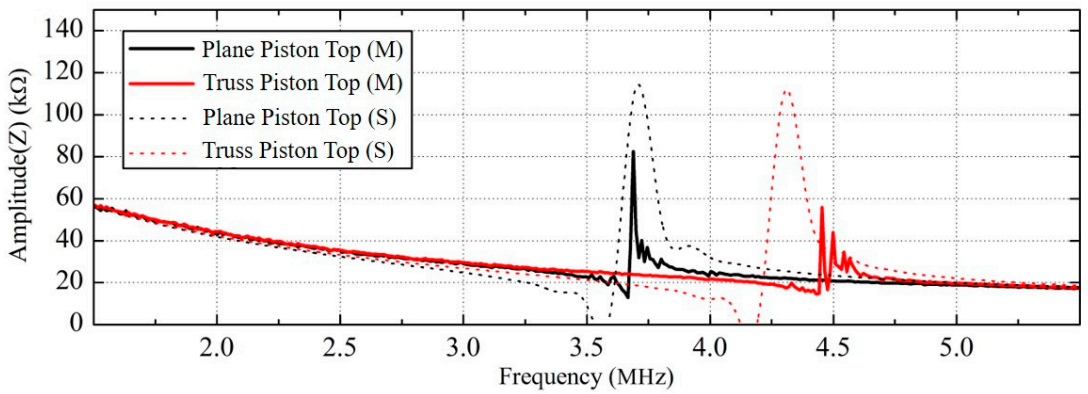

(a)

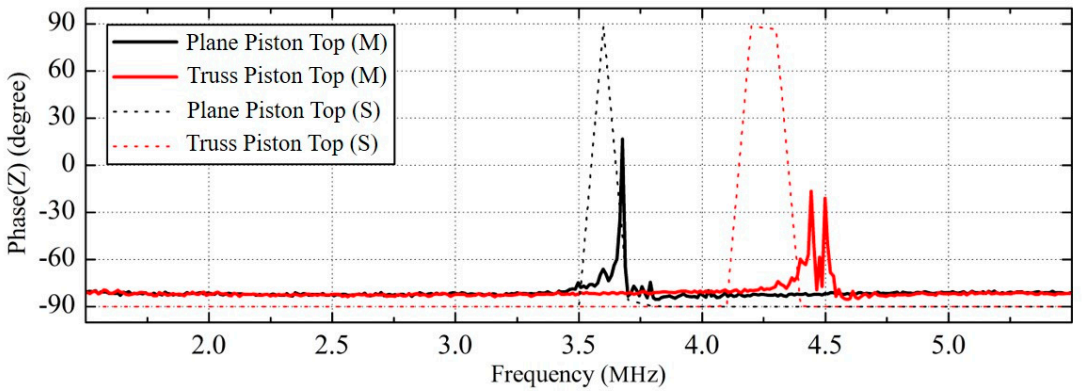

(b)

Figure 5. Electrical input impedance measurement results of the plane and truss 2D CMUTs biased at 40 V DC in air: (a) the amplitude part and (b) the phase part. The dotted line represented the ANSYS simulation results of each type of the CMUTs.
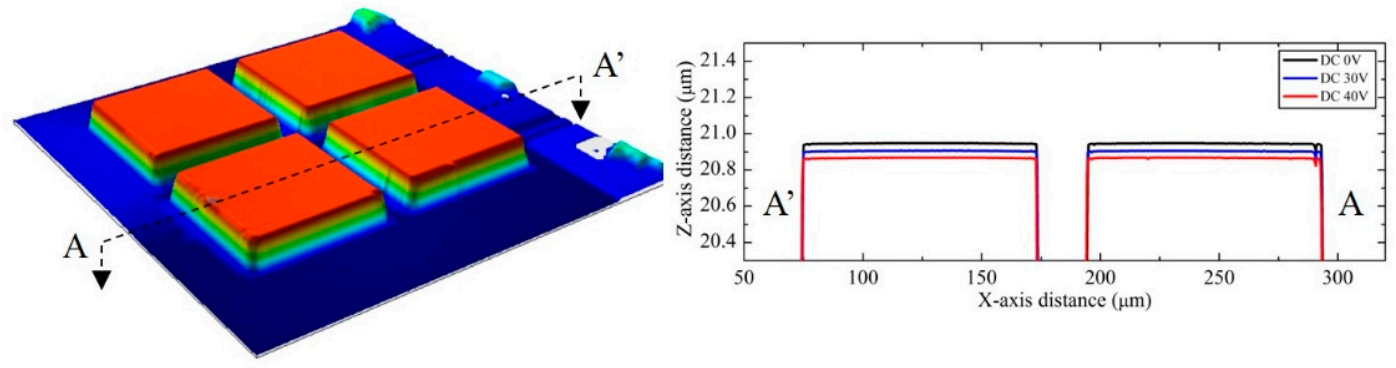

(a)
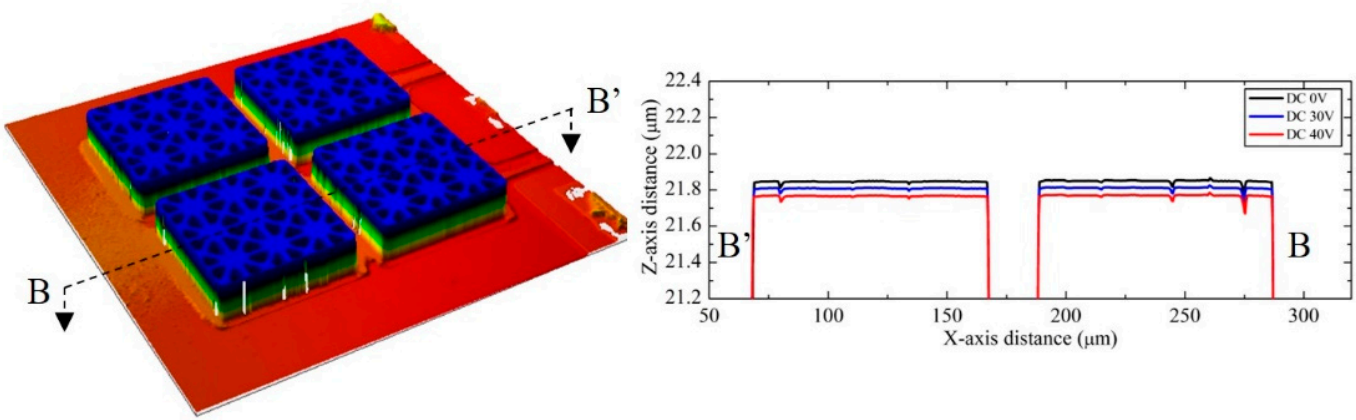

(b)

Figure 6. (a) A 3D surface profile of the plane 2D CMUT element at $0 \mathrm{~V}$ DC bias, and its corresponding 2D profile plot along the line $\mathrm{A}-\mathrm{A}^{\prime}$ at different $\mathrm{DC}$ biases, $0 \mathrm{~V}$ (black), $30 \mathrm{~V}$ (blue), and $40 \mathrm{~V}$ (red), respectively. (b) A 3D surface profile of the truss 2D CMUT element at $0 \mathrm{~V} \mathrm{DC}$ bias, and its corresponding 2D profile plot along the line $\mathrm{B}-\mathrm{B}^{\prime}$ at different $\mathrm{DC}$ biases, $0 \mathrm{~V}$ (black), $30 \mathrm{~V}$ (blue), and $40 \mathrm{~V}$ (red), respectively. 
The dynamic response of the 2D CMUT elements with substrate-embedded springs, was measured using a laser Doppler vibrometer (OFV-511, Polytec GmbH, Waldbronn, Germany) with in-house custom-built microscopy. The laser focused from the lens was scanned for 40 steps with a step size of $10 \mu \mathrm{m}$, along the $X$ and $Y$ axes. An AC function generator (Agilent 33250A, Agilent, Inc., Santa Clara, CA, USA), was connected to an in-house custom-built interface printed circuit board for applying the bias voltage and the AC signal to the CMUT devices. With a DC bias voltage of $40 \mathrm{~V}$ superposed onto a continuous wave pulse of $1 \mathrm{~V}$ and $3.5 \mathrm{MHz}$, Figure 7a explicitly demonstrates the nonflexural parallel piston movement of the plane top plate in air. In addition, the measurement verifies that all four piston top plates were in-phase during the transduction. The maximum peak-to-peak displacement efficiency in air was $12 \mathrm{~nm} / \mathrm{V}$, which was almost the same as the maximum average displacement efficiency (Figure $7 \mathrm{~b}$ ). The measurement of the dynamic displacement was also examined in soybean oil using the truss element. The CMUT device was excited using a unipolar rectangular pulse of $20 \mathrm{~V}$ and $2 \mathrm{MHz}$. The device was initially biased with a 35 V DC voltage. Figure 7c shows a three-dimensional (3D) perspective view of the truss piston plate displacement at the maximum positive peak. The maximum peak-to-peak displacement efficiency in oil, was calculated to be $1.1 \mathrm{~nm} / \mathrm{V}$, as shown in Figure $7 \mathrm{~d}$.

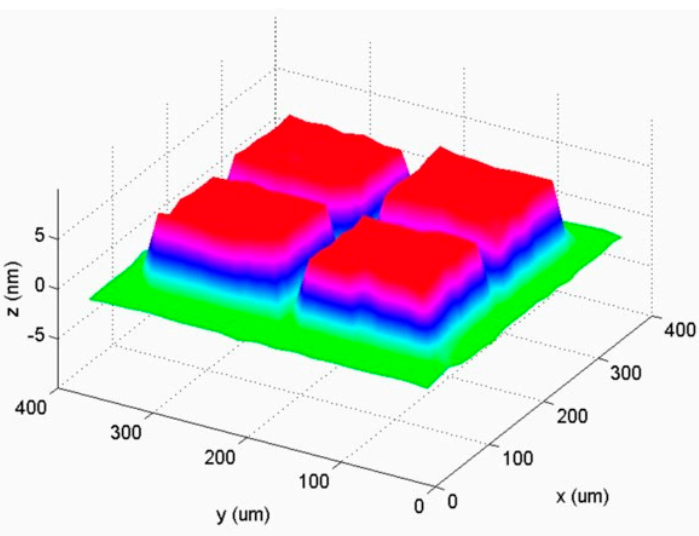

(a)

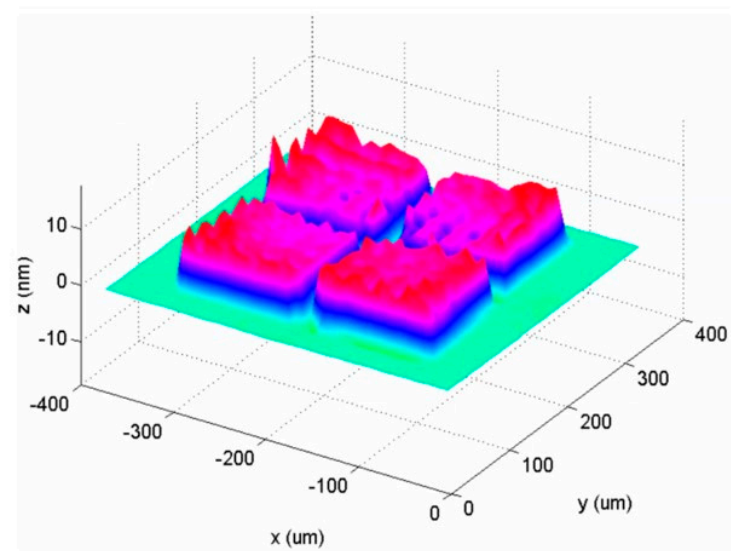

(c)

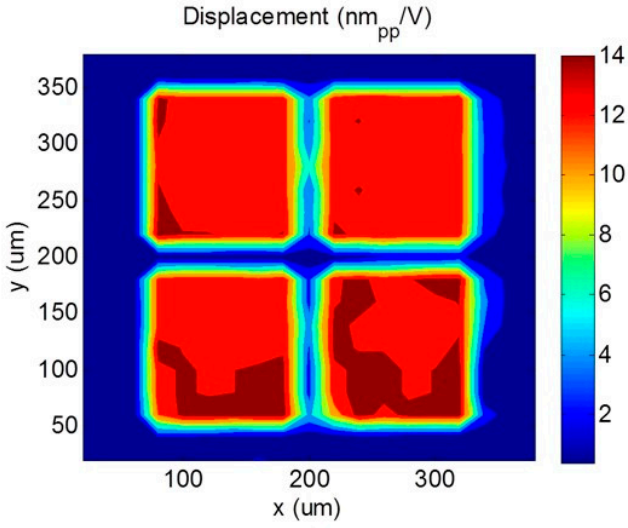

(b)

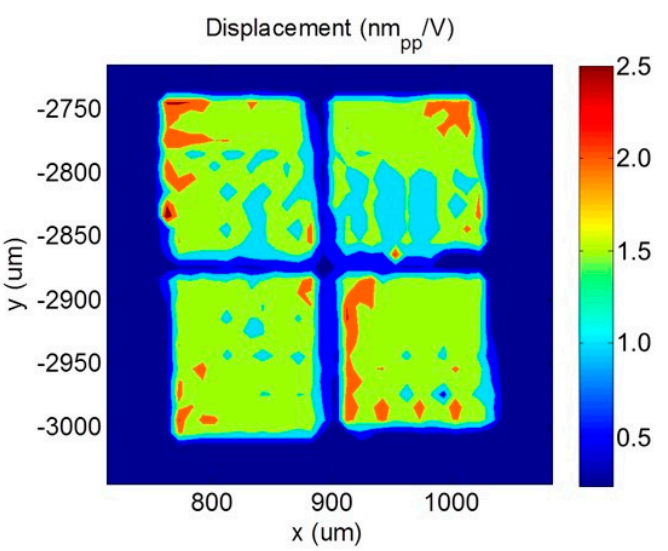

(d)

Figure 7. The dynamic plate displacement measurements from a laser Doppler vibrometer. (a) A 3D perspective view at the moment of the positive maximum peak displacement of the plane $2 \mathrm{D}$ CMUT element in air and (b) its contour plot of the maximum peak-to-peak displacement over the measurement time. (c) A 3D perspective view at the moment of the positive maximum peak displacement of the truss 2D CMUT element in oil and (d) its contour plot of the maximum peak-to-peak displacement over the measurement time. 
A hydrophone measurement was carried out in immersion to obtain the maximum output pressure and the transmission efficiency. A hydrophone (HGL-0200, Onda, Co., Sunnyvale, CA, USA), linked with a pre-amplifier was connected to a digitizing oscilloscope (Infiniium 54825A, Agilent, Inc., Santa Clara, CA, USA), and immersed in oil to monitor the pressure field from the 2D CMUT elements. The plane 2D CMUT element was biased at $55 \mathrm{~V}$, which was about $70 \%$ of the pull-in voltage. A $2 \mathrm{MHz}$, $90 \mathrm{~V}$ peak-to-peak single sine pulse was superposed onto the DC bias voltage. The plane 2D CMUT, operated in the normal mode but not in the collapse mode because, the single sine pulse did not make the system statically in-phase and transiently drove the CMUT; even though the arithmetic sum of the applied voltage exceeded the pull-in DC voltage [23]. The distance between the hydrophone and the 2D CMUT element was set to be $3.7 \mathrm{~mm}$, which was sufficient to detect the far-field signal after the focal zone. Figure 8 shows the transient pressure amplitude and its frequency spectrum for the plane 2D CMUT element. The output pressure at the surface of the 2D CMUT element, was calculated considering the attenuation and diffraction loss in the medium [24]. The corresponding maximum transient pressure at the surface was $1.88 \mathrm{MPa}$ peak-to-peak, with a transmission efficiency of $21 \mathrm{kPa} / \mathrm{V}$. Using Equation (3), the maximum average displacement efficiency was calculated to be $1.13 \mathrm{~nm} / \mathrm{V}$. The calculated maximum average displacement efficiency was closely matched to the measurement from the laser Doppler vibrometer. As shown in Figure 8b, a -3 dB FBW of $81 \%$ around the center frequency of $1.85 \mathrm{MHz}$ was obtained.

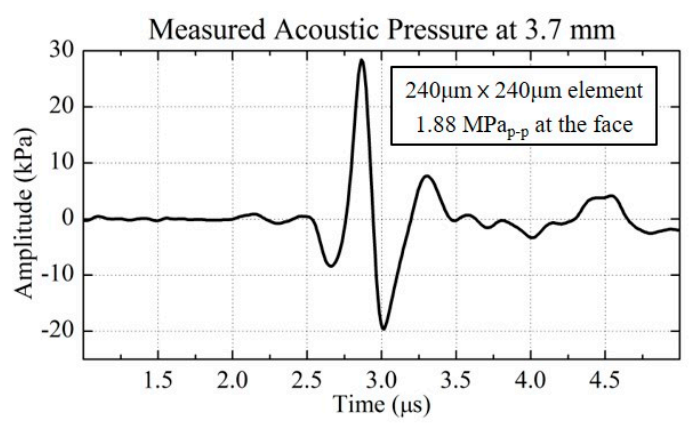

(a)



(b)

Figure 8. Measured acoustic pressure of the plane 2D CMUT element at $3.7 \mathrm{~mm}$ distance. (a) Transient pressure and (b) its frequency spectrum.

\section{Transmit Efficiency Comparison of PZT Ceramic vs. CMUT with Substrate-Embedded Springs}

We compared the measurement data of our device with FEA simulation data of a lead zirconate titanate (PZT) ceramic HD3203 (CTS Corp., Lisle, IL, USA), a PZT ceramic PZ21 (Meggitt A/S, Kvistgaard, Denmark), and a single crystal PMN-33\% $\mathrm{PT}\left(0.67 \mathrm{~Pb}\left(\mathrm{Mg}_{0.33} \mathrm{Nb}_{0.67}\right) \mathrm{O}_{3}-0.33 \mathrm{PbTiO}_{3}\right)$ from literature in Reference [25]. We also measured the pressure field, of a commercial PZT probe (model SP1-5, Alpinion Medical Systems, Co., Ltd., Anyang, Korea). Table 1 summarizes the hydrophone measurement results of the 1D phased array PZT probe. Table 2 summarizes the transmission performance comparison between the PZT ceramic HD3203; the PZT ceramic PZ21; the single crystal PMN-0.33PT; the measured commercial PZT probe; and the 2D CMUT element with substrate-embedded springs. Although single crystal piezoelectric materials, such as lead magnesium niobate-lead titanate (PMN-PT), and lead zinc niobate-lead titanate (PZN-PT) generally offer the highest transmission efficiency, the 2D CMUT element outperformed the two PZT ceramics HD3203 and PZ21, and the commercial 1D phased array probe in the maximum output pressure efficiency or the average volume displacement efficiency by 1.35 times, 1.40 times, and 1.59 times. The measured average volume displacement efficiency of the CMUT reached almost $80 \%$ of the simulated value of the PMN-0.33PT. In the FEA data of the two PZT ceramic materials and the single crystal PMN-0.33PT, the simulation was performed with the ideal backing layer model which was assumed to be infinitely 
thick, while the hydrophone measurement results showed that all the acoustic attenuation and loss were considered. Thus, taking this possible loss of the ideal PMN-0.33PT performance into account, the 2D CMUT element can provide an almost comparable average volume displacement efficiency of the state-of-the-art single-crystal piezoelectric materials. Also, since lead-containing materials possibly cause harmful effects on the environment and public health [26,27], the comparison result showed that the 2D CMUT element with the comparable transmission performance of the PZT ceramics, could be one of the alternatives to the lead-based piezoelectric materials.

Table 1. Hydrophone measurement result of the 1D phased array lead zirconate titanate (PZT) probe.

\begin{tabular}{ccccccc}
\hline $\begin{array}{c}\text { TX Frequency } \\
\text { (MHz) }\end{array}$ & $\mathbf{V}_{\mathbf{p p}}$ & $\begin{array}{c}\text { Pressure @ Focal } \\
\text { Spot (Mpa) }\end{array}$ & $\begin{array}{c}\text { Element } \\
\text { Number }\end{array}$ & Focus (mm) & $\begin{array}{c}\text { Acoustic } \\
\text { Gain }\end{array}$ & $\begin{array}{c}\text { Attenuation } \\
(\mathbf{d B} / \mathbf{M H z} / \mathbf{m m})\end{array}$ \\
\hline 2.00 & 30 & 0.66 & 64 & 52 & 2.21 & 0.75 \\
2.00 & 45 & 1.04 & 64 & 52 & 2.21 & 0.75 \\
2.00 & 60 & 1.33 & 64 & 52 & 2.21 & 0.75 \\
\hline
\end{tabular}

Table 2. Transmission performance comparison between PZT ceramics 3203HD, PZ21 and the CMUT with substrate-embedded springs.

\begin{tabular}{|c|c|c|c|c|c|}
\hline & $\begin{array}{l}\text { PZT Ceramic } \\
(3203 \mathrm{HD})^{1}\end{array}$ & $\begin{array}{l}\text { PZT Ceramic } \\
\quad\left(\text { PZ21) }^{1}\right.\end{array}$ & $\begin{array}{l}\text { PZT Ceramic } \\
(\text { PMN-0.33PT })^{1}\end{array}$ & $\begin{array}{l}\text { A Commercial } \\
\text { PZT Probe }^{2}\end{array}$ & $\begin{array}{c}\text { CMUT with } \\
\text { Substrate-Embedded } \\
\text { Springs }\end{array}$ \\
\hline Frequency (MHz) & 1.85 & 1.85 & 1.85 & 2.00 & 1.85 \\
\hline Max. Pressure (kPa) & $\begin{array}{c}1431 \\
\text { @ } 90 \mathrm{~V}_{\mathrm{pp}}\end{array}$ & $\begin{array}{c}924 \\
@ 60 \mathrm{~V}_{\mathrm{pp}}\end{array}$ & $\begin{array}{c}2457 \\
@ 90 \mathrm{~V}_{\mathrm{pp}}\end{array}$ & $\begin{array}{c}802 \\
\text { @ } 60 \mathrm{~V}_{\mathrm{pp}}\end{array}$ & $\begin{array}{c}1880^{3} \\
\text { @ } 90 \mathrm{~V}_{\mathrm{pp}}\end{array}$ \\
\hline $\begin{array}{l}\text { Transmit Pressure } \\
\text { Efficiency }(\mathrm{kPa} / \mathrm{V})\end{array}$ & 15.9 & 15.4 & 27.3 & 13.4 & 21.5 \\
\hline $\begin{array}{c}\text { Average Volume } \\
\text { Displacement } \\
\text { Efficiency }^{4}(\mathrm{~nm} / \mathrm{V})\end{array}$ & 0.804 & 0.779 & 1.43 & 0.711 & 1.13 \\
\hline
\end{tabular}

\section{Conclusions}

We have shown the concept, fabrication, and characterization of CMUT elements with substrate-embedded springs achieving high output pressure efficiency. The nonflexural parallel piston plate movement of the device, by the embedded springs induces high average volume displacement efficiency with low DC and AC voltage. With its high efficiency and low voltage operation, we believe the CMUT with substrate-embedded springs can be significantly applied to medical applications such as HIFU, ultrasound elastography, point-of-care, and portable/wearable devices. Since the CMUT has the advantage of being fabricated in 2D arrays and integrated with integrated circuits, we plan to fabricate 1D CMUT arrays and systemize them for acoustic radiation force impulse imaging.

Author Contributions: A.N. and B.T.K.-Y. conceived and initiated the project; B.C.L., A.N. and K.K.P. designed the experiments; B.C.L. and A.N. fabricated the devices; B.C.L., A.N. and K.K.P. measured the data; B.C.L., A.N., K.K.P. and B.T.K.-Y. analyzed the data; B.C.L. and B.T.K.-Y. contributed funding acquisition for the study; B.C.L., A.N., K.K.P. and B.T.K.-Y. wrote and reviewed the manuscript.

Funding: This research was funded by the National Institutes of Health (NIH) grant number R01HL117740, Analog Devices grant, and the KIST institutional Program grant number 2E27910.

Acknowledgments: All the fabrication was performed at the Stanford Nanofabrication Facility (Stanford, CA, USA), a member of the National Nanotechnology Infrastructure Network. All the SEM/FIB pictures were obtained at the Stanford Nano Center (SNC)/Stanford Nano-characterization Laboratory (SNL), part of the Stanford Nano Shared Facilities.

Conflicts of Interest: The authors declare no conflicts of interest. 


\section{References}

1. Khuri-Yakub, B.T.; Oralkan, Ö.; Kupnik, M. Next-gen ultrasound. IEEE Spectr. 2009, 46, 44-54. [CrossRef]

2. Bhuyan, A.; Choe, J.W.; Lee, B.C.; Wygant, I.O.; Nikoozadeh, A.; Oralkan, Ö.; Khuri-Yakub, B.T. Integrated circuits for volumetric ultrasound imaging with 2-D CMUT arrays. IEEE Trans. Biomed. Circuits Syst. 2013, 7, 796-804. [CrossRef] [PubMed]

3. Engholm, M.; Bouzari, H.; Christiansen, T.L.; Beers, C.; Bagge, J.P.; Moesner, L.N.; Diederichsen, S.E.; Stuart, M.B.; Jensen, J.A.; Thomsen, E.V. Probe development of CMUT and PZT row-column-addressed 2-D arrays. Sens. Actuator A Phys. 2018, 273, 121-133. [CrossRef]

4. Savoia, A.S.; Caliano, G.; Pappalardo, M. A CMUT Probe for medical ultrasonography: From microfabrication to system integration. IEEE Trans. Ultrason. Ferroelectr. Freq. Control 2012, 59, 1127-1138. [CrossRef] [PubMed]

5. Daya, I.B.; Chen, A.I.H.; Shafiee, M.J.; Wong, A.; Yeow, J.T.W. Compensated row-column ultrasound imaging system using multilayered edge guided stochastically fully connected random fields. Sci. Rep. 2017, 7, 10644. [CrossRef] [PubMed]

6. Chen, K.; Lee, B.C.; Thomenius, K.E.; Khuri-Yakub, B.T.; Lee, H.-S.; Sodini, C.G. A column-row-parallel ultrasound imaging architecture for 3-D plane-wave imaging and Tx second-order harmonic distortion reduction. IEEE Trans. Ultrason. Ferroelectr. Freq. Control 2018, 65, 828-843. [CrossRef] [PubMed]

7. Nikoozadeh, A.; Wygant, I.O.; Lin, D.-S.; Oralkan, Ö.; Ergun, A.S.; Stephens, D.N.; Thomenius, K.E.; Dentinger, A.M.; Wildes, D.; Akopyan, G.; et al. Forward-looking intracardiac ultrasound imaging using a 1-D CMUT array integrated with custom front-end electronics. IEEE Trans. Ultrason. Ferroelectr. Freq. Control 2008, 55, 2651-2660. [CrossRef] [PubMed]

8. Khuri-Yakub, B.T.; Oralkan, Ö. Capacitive micromachined ultrasonic transducers for medical imaging and therapy. J. Micromech. Microeng. 2011, 21, 054004. [CrossRef] [PubMed]

9. Choe, J.W.; Oralkan, Ö.; Nikoozadeh, A.; Gencel, M.; Stephens, D.N.; O’Donnell, M.; Sahn, D.J.; Khuri-Yakub, B.T. Volumetric real-time imaging using a CMUT ring array. IEEE Trans. Ultrason. Ferroelectr. Freq. Control 2012, 59, 1201-1211. [CrossRef] [PubMed]

10. Gurun, G.; Tekes, C.; Zahorian, J.; Xu, T.; Satir, S.; Karaman, M.; Hasler, J.; Degertekin, F.L. Single-chip CMUT-on-CMOS front-end system for real-time volumetric IVUS and ICE imaging. IEEE Trans. Ultrason. Ferroelectr. Freq. Control 2014, 61, 239-250. [CrossRef] [PubMed]

11. Yoon, H.S.; Chang, C.L.; Jang, J.H.; Bhuyan, A.; Choe, J.W.; Nikoozadeh, A.; Watkins, R.; Stephens, D.; Butts Pauly, K.; Khuri-Yakub, B.T. Ex vivo HIFU experiments using a $32 \times 32$-element CMUT array. IEEE Trans. Ultrason. Ferroelectr. Freq. Control 2016, 63, 2150-2158. [CrossRef] [PubMed]

12. Vallet, M.; Varray, F.; Boutet, J.; Dinten, J.-M.; Caliano, G.; Savoia, A.S.; Vray, D. Quantitative comparison of PZT and CMUT probes for photoacoustic imaging: Experimental validation. Photoacoustics 2017, 8, 48-58. [CrossRef] [PubMed]

13. Huang, Y.; Zhuang, X.; Hggstrom, E.; Ergun, A.S.; Cheng, C.-H.; Khuri-Yakub, B.T. Capacitive micromachined ultrasonic transducers with piston-shaped membranes: Fabrication and experimental characterization. IEEE Trans. Ultrason. Ferroelectr. Freq. Control 2009, 56, 136-145. [CrossRef] [PubMed]

14. Guldiken, R.O.; Zahorian, J.; Yamaner, F.Y.; Degertekin, F.L. Dual-electrode CMUT with non-uniform membranes for high electromechanical coupling coefficient and high bandwidth operation. IEEE Trans. Ultrason. Ferroelectr. Freq. Control 2009, 56, 1270-1276. [CrossRef] [PubMed]

15. Kim, D.K.; Chung, S.-W.; Jeong, B.-G.; Hong, S.-W.; Shin, H. An indirectly clamped capacitive micromachined ultrasonic transducer with a high electromechanical coupling factor. Sens. Actuator A Phys. 2013, 203, 82-91. [CrossRef]

16. Emadi, T.A.; Buchanan, D.A. A novel $6 \times 6$ element MEMS capacitive ultrasonic transducer with multiple moving membranes for high performance imaging applications. Sens. Actuator A Phys. 2015, 222, 309-313. [CrossRef]

17. Yu, Y.; Pun, S.H.; Mak, P.U.; Cheng, C.-H.; Wang, J.; Mak, P.-I.; Vai, M.I. Design of a collapse-mode CMUT with an embossed membrane for improving output pressure. IEEE Trans. Ultrason. Ferroelectr. Freq. Control 2016, 63, 854-863. [CrossRef] [PubMed]

18. Ventsel, E.; Krauthammer, T. Thin Plates and Shells: Theory, Analysis, and Applications; Marcel Dekker, Inc.: New York, NY, USA, 2001; ISBN 0-8247-0575-0. 
19. Nikoozadeh, A.; Bayram, B.; Yaralioglu, G.G.; Khuri-Yakub, B.T. Analytical calculation of collapse voltage of CMUT membrane. In Proceedings of the IEEE Ultrasonics Symposium, Montreal, QC, Canada, 23-27 August 2004; pp. 256-259. [CrossRef]

20. Morse, P.M.; Ingard, K.U. Theoretical Acoustics; McGraw-Hill Book Company, Inc.: New York, NY, USA, 1968; ISBN 0-691-08425-4.

21. Lee, B.C.; Nikoozadeh, A.; Park, K.K.; Khuri-Yakub, B.T. Understanding CMUTs with substrate-embedded springs. In Proceedings of the IEEE Ultrasonics Symposium, Orlando, FL, USA, 18-21 October 2011; pp. 1008-1011. [CrossRef]

22. Lee, B.C.; Nikoozadeh, A.; Park, K.K.; Khuri-Yakub, B.T. Non-flexural parallel piston movement across CMUT with substrate-embedded springs. In Proceedings of the IEEE Ultrasonics Symposium, Chicago, IL, USA, 3-6 September 2014; pp. 591-594. [CrossRef]

23. Park, K.K.; Oralkan, O.; Khuri-Yakub, B.T. A comparison between conventional and collapse-mode capacitive micromachined ultrasonic transducers in 10-MHz 1-D arrays. IEEE Trans. Ultrason. Ferroelectr. Freq. Control 2013, 60, 1245-1255. [CrossRef] [PubMed]

24. Kino, G.S. Acoustic Waves: Devices, Imaging, and Analog Signal Processing; Prentice Hall, Inc.: Englewood Cliffs, NJ, USA, 1987; ISBN 0-13-003047-3.

25. Frijlink, M.E.; Torp, H. Simulation of acoustic fields from arbitrary transducer stacks using a FEM transducer model and nonlinear wave propagation. In Proceedings of the IEEE Ultrasonics Symposium, Roma, Italy, 20-23 September 2009; pp. 2340-2343. [CrossRef]

26. Panda, P.K. Review: Environmental friendly lead-free piezoelectric materials. J. Mater. Sci. 2009, 44, 5049-5062. [CrossRef]

27. Gordon, J.N.; Taylor, A.; Bennett, P.N. Lead poisoning: Case studies. Br. J. Clin. Pharmacol. 2002, 53, 451-458. [CrossRef] [PubMed]

(C) 2018 by the authors. Licensee MDPI, Basel, Switzerland. This article is an open access article distributed under the terms and conditions of the Creative Commons Attribution (CC BY) license (http:/ / creativecommons.org/licenses/by/4.0/). 